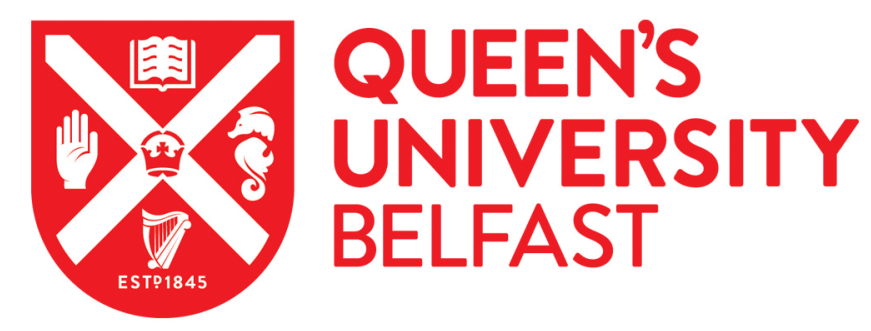

\title{
Guest Editorial: special cluster on recent advances in antennas for Earth and planetary science
}

Yurduseven, O., Khalily, M., Podilchak, S., Chattopadhyay, G., \& Fonseca, N. (2021). Guest Editorial: special cluster on recent advances in antennas for Earth and planetary science. IEEE Antennas and Wireless

Propagation Letters, 20(11), 2083 - 2084. https://doi.org/10.1109/LAWP.2021.3115227

Published in:

IEEE Antennas and Wireless Propagation Letters

Document Version:

Peer reviewed version

Queen's University Belfast - Research Portal:

Link to publication record in Queen's University Belfast Research Portal

Publisher rights

Copyright 2021, IEEE

This work is made available online in accordance with the publisher's policies. Please refer to any applicable terms of use of the publisher.

\section{General rights}

Copyright for the publications made accessible via the Queen's University Belfast Research Portal is retained by the author(s) and / or other copyright owners and it is a condition of accessing these publications that users recognise and abide by the legal requirements associated with these rights.

Take down policy

The Research Portal is Queen's institutional repository that provides access to Queen's research output. Every effort has been made to ensure that content in the Research Portal does not infringe any person's rights, or applicable UK laws. If you discover content in the Research Portal that you believe breaches copyright or violates any law, please contact openaccess@qub.ac.uk. 


\section{Guest Editorial: Special Cluster on Recent Advances in Antennas for Earth and Planetary Science}

$\mathrm{R}$ ESEARCH into innovative antenna technologies has been growing rapidly with the invention of emerging techniques to manipulate the electromagnetic (EM) waves and their propagation. These efforts have been supported by the increasing demands in wireless technologies in general, covering a wide application spectrum, from $5 \mathrm{G}$ and beyond to Earth and Planetary science. Antenna design for Earth and Planetary science can be particularly challenging. In fact, it can be argued that the interest in these efforts has not been motivated purely by the antenna performance. Rather, a significant challenge has been to achieve the ideal antenna performance by taking into account the environmental and mission specific instrument budget requirements, including but not limited to: the ability to work in extreme environments, satisfy the weight, space, and power consumption limits for the mission specific instrument for launch. As a result, the development of low-weight, low-profile, cost-effective and robust antenna architectures without sacrificing the antenna performance has been the holy grail of research efforts conducted in this field. In light of this, recent advances in this community have gradually evolved to include unusual types of antenna solutions, such as reflectarrays, metasurfaces, photovoltaic antennas and all-metal antennas for harsh environments with promising results.

The objective of this special cluster is to bring together the antenna community to present the state-of-the-art research conducted in this field and highlight the emerging antenna technologies in addressing the Earth and Planetary science instrumentation. This special cluster aims to present some examples of the latest advances in antenna technology for Earth and Planetary science. Among these antenna topologies, a particular emphasis should be given to metasurface type of antennas. A metasurface can be considered a two-dimensional (2D) surface synthesized using an array of sub-wavelength sized unit-cells. Such surfaces can manipulate the behavior of EM waves to achieve the desired transmission, reflection, polarization and radiation responses. Particularly, operating in a reflection mode, such surfaces have received substantial interest in the context of reflectrarrays. E. C. Pelletier et al. present a dual-polarized reflectarray antenna operating at $\mathrm{Ku}$ band frequencies to synthesize a synthetic aperture radar (SAR) for snow mass measurements. The proposed design is also installed on a CubeSat platform to verify its performance in the presence of solar cells. The final prototype of the reflectarray represents a promising solution for remote sensing missions on CubeSat platforms. Another design of a reflecting surface is presented by L. Leszkowska et al., leveraging a partially reflecting surface (PRS) to synthetize high-gain and circularlypolarized radiation characteristics at X-band frequencies. The proposed structure uses a circularly-polarized single-fed patch exciting a PRS surface as a superstrate layer loaded with unitcells exhibiting spatially modulated geometrical features to synthesize the desired phase response across the PRS. The lowprofile structure of the proposed design makes it a suitable candidate for CubeSat integration as well as for drones and high-altitude pseudo-satellite applications.

An interesting concept is the filtenna structure, involving the combination of a filter topology with an antenna that can be tailored to radiate a specific radiation pattern. M. Patriotis et al. propose an active Ka-Band filtenna with a right-hand circularly polarized (RHCP) radiation that can be reconfigured between two center frequencies at Ka-band frequencies. The antenna uses PIN diodes to achieve frequency reconfiguration and exhibits a single-layer architecture, ideal for CubeSat integration.

Three-dimensional (3D) printing of EM structures has advanced significantly over the last decade, with an increasing amount of research being conducted in this area. C. Turkmen et al. present an omnidirectional and circularly polarized dualband antenna for telemetry/telecommand (TMTC) applications in satellite communications at $\mathrm{Ku}$-band frequencies. The antenna exhibits a single waveguide feed and no dielectric, making it an excellent candidate to be used as a high-power transceiver on a satellite.

G. Addamo et al. demonstrate a $\mathrm{Ku} / \mathrm{Ka}$ dual-band feed horn topology developed for the Copernicus Imaging Microwave Radiometer (CIMR). The presented design, when used as a feed horn, meets several challenging requirements needed for the Copernicus Earth observation program, including exhibiting a low footprint, a high radiation efficiency, a narrow beamwidth and low cross-polarization levels.

Q. Garcia et al. present a hybrid analog/digital SAR beamforming for Earth observation. The developed SAR instrument leverages analog beamforming on transmit and hybrid analog/digital beamforming on receive, while using a feed array topology to feed a reflector aperture at L-band frequencies. The resulting system allows for both dualpolarization (VV-HH) and quad-polarization (VV-HH-VHHV) operations of the SAR instrument.

$\mathrm{K}$. Y. Zhong et al. present a new beam forming method as an enabling technology to meet the coverage requirement of the effective isotropic radiated power (EIRP) and achieve multibeam coverage in Low Earth Orbit (LEO) satellites. The developed subarray multi-beam forming method is proven to be an effective solution to achieve optimal coverage in LEO 
satellites.

$\mathrm{K}$. Alrushud et al. demonstrate a quasi-end-fire surface-wave antenna integrated with a CubeSat platform. The antenna exhibits a leaky-wave surface-integrated-waveguide (SIW) launcher with an extremely low-profile, making it a suitable candidate for CubeSat integration. In another interesting CubeSat antenna design, M. Kuznetcov et al. present a leakywave antenna using a SIW technology to achieve dual-band broadside radiation at K-band frequencies. Circularly-polarized radiation from the developed leaky-wave antenna is also demonstrated while the effect of CubeSat integration on the antenna performance is studied in detail.

In closing, the Guest Editors would like to express their gratitude to the reviewers and the authors. Their effort and contribution have made this special cluster possible. We also would like to sincerely thank the IEEE Antennas and Wireless Propagation Letters Editor-in-Chief, Prof. C. Fumeaux, and the Editorial Assistant, C. Sideri, for their professionalism, patience and magnificent support. Finally, we hope that this special cluster will foster new research ideas and generate new frontiers in innovative antenna technologies for Earth and Planetary science, and hence, will immensely benefit the IEEE Antennas and Wireless Propagation Letters community.

Okan Yurduseven, Guest Editor

Queen's University Belfast

Belfast, BT3 9DT, United Kingdom

Mohsen Khalily, Guest Editor

University of Surrey

Guildford, GU2 7XH, United Kingdom

Symon Podilchak, Guest Editor

University of Edinburgh

Edinburgh, EH14 4AS, United Kingdom

Goutam Chattopadhyay, Guest Editor

NASA Jet Propulsion Laboratory

Pasadena, California 91109, United States

Nelson Fonseca, Guest Editor

European Space Agency

2200 AG Noordwijk, Netherlands 


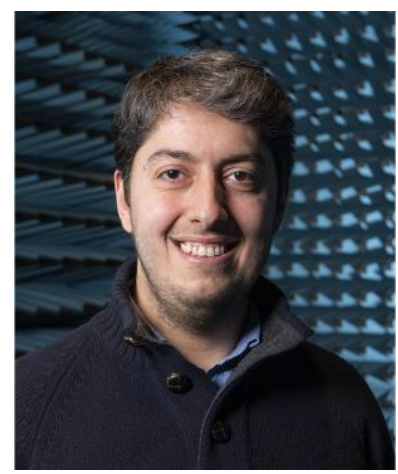

Okan Yurduseven (S'09-M'11-SM'16) received the B.Sc. and M.Sc. degrees in electrical engineering from Yildiz Technical University, Istanbul, Turkey, in 2009 and 2011, respectively, and the Ph.D. degree in electrical engineering from Northumbria University, Newcastle upon Tyne, United Kingdom in 2014.

$\mathrm{He}$ is currently a Senior Lecturer (Associate Professor) at the School of Electronics, Electrical Engineering and Computer Science, Queen's University Belfast, UK. He is also an Adjunct Professor at Duke University, USA. Between 2018-2019, he was a NASA Research Fellow at the Jet Propulsion Laboratory, California Institute of Technology, USA. From 2014 to 2018, he was a Postdoctoral Research Associate within the Department of Electrical and Computer Engineering at Duke University, USA.

His research interests include microwave and millimeter-wave imaging, multiple-input-multipleoutput (MIMO) radars, wireless power transfer, antennas and propagation and metamaterials. He has authored more than 140 peer-reviewed technical journal and conference articles, and has been the Principal Investigator on research grants totaling in excess of $£ 1.3 \mathrm{M}$ in these fields. He has served as a Technical Program Committee Member in SPIE Defense and Commercial Sensing conference since 2020 and a Guest Editor in several journals, including IEEE Antennas and Wireless Propagation Letters, IEEE Open Journal of Antennas and Propagation and MDPI Remote Sensing.

In 2017, Dr Yurduseven received an Outstanding Postdoctoral Award from Duke University. He was the recipient of the NASA Postdoctoral Program Fellowship administrated by Universities Space Research Association (USRA) in 2018. In 2019, in collaboration with the University of Limoges, France, he received the Alliance Hubert Curien Award funded by the British Council. In 2020, he was bestowed the Leverhulme Trust Research Leadership Award. He serves as an Associate Editor of the IEEE Antennas and Wireless Propagation Letters and MDPI Remote Sensing, and is a member of the European Association on Antennas and Propagation (EurAAP).

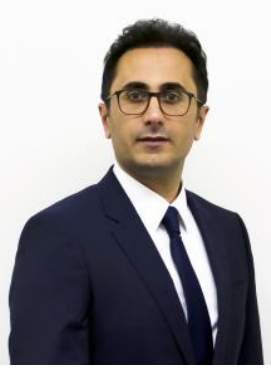

Mohsen Khalily (M'13-SM'18) is a Lecturer in Antenna and Propagation with the Institute for Communication Systems (ICS), Home of the 5G and 6G Innovation Centres (5GIC \& 6GIC), University of Surrey, U.K., where he was a Research Fellow on antennas and propagation from December 2015 to March 2019. Prior to joining the 5GIC he was a Senior Lecturer with the Wireless Communication Centre (WCC), University Technology Malaysia (UTM). He is a Fellow of the U.K. Higher Education Academy and an IEEE Senior Member.

He has published almost 120 academic papers in international peer-reviewed journals and conference proceedings. His research interests include Surface Electromagnetic, Reconfigurable Reflecting Surface, 5G system, Phased Arrays, Hybrid Beamforming, mm-Wave\&Terahertz antennas and propagation has been the Principal Investigator on research grants totaling in excess of $£ 900 \mathrm{k}$ in these fields. He is also a member of the IEEE Antennas and Propagation Society, the IEEE Communication Society, and the IEEE Microwave Theory and Techniques Society; and an Associate Editor of the IEEE Access.

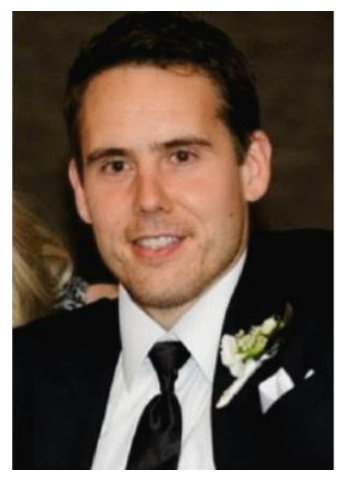

Symon K. Podilchak (S'03-M'05) received the B.A.Sc. degree in engineering science from the University of Toronto, Toronto, ON, Canada, in 2005, and the M.A.Sc. and Ph.D. degrees in electrical engineering from Queens University, Kingston, ON, Canada, in 2008 and 2013, respectively. From 2013 to 2015, he was an Assistant Professor with Queens University. In 2015, he joined HeriotWatt University, Edinburgh, U.K., as an Assistant Professor, and became an Associate Professor in 2017. He is currently a Senior Lecturer with the School of Engineering, The University of Edinburgh, Edinburgh, Scotland. His research interests include surface waves, leaky-wave antennas, metasurfaces, UWB antennas, phased arrays, and RF integrated circuits. He is also a Registered Professional Engineer (P.Eng.) and has had industrial experience as a computer programmer, and has designed 24 and $77 \mathrm{GHz}$ automotive radar systems with Samsung and Magna Electronics. Recent industry experience also includes the design of high frequency surfacewave radar systems, professional software design and implementation for measurements in anechoic chambers for the Canadian Department of National Defence and the SLOWPOKE Nuclear Reactor Facility. He has also designed compact antennas for wideband military communications, highly compact circularly polarized antennas for CubeSats with COM DEV International (now Honeywell Cambridge COM DEV) and The European Space Agency (ESA), and, new wireless power transmission systems for Samsung. Dr. Podilchak and his students have been the recipient of many best paper awards and scholarships, most notably Research Fellowships from the IEEE Antennas and Propagation Society (AP-S), the IEEE Microwave Theory and Techniques Society (MTT-S), the European Microwave Association, and six Young Scientist Awards from the International Union of Radio Science (URSI). He was also the recipient of the Postgraduate Fellowship from the Natural Sciences and Engineering Research Council of Canada (NSERC). In 2011, 2013 and 2020, Student Paper Awards were received at the IEEE International Symposium on Antennas and Propagation, and in 2012, he was the recipient of the Best Paper Prize for Antenna Design at the European Conference on Antennas and Propagation for his 
work on CubeSat antennas, and in 2016, the European Microwave Prize for his research on surface waves and leaky-wave antennas. In 2017 and 2019, he was bestowed a Visiting Professorship Award at Sapienza University, Rome, Italy, and from 2016 to 2019 , his research was supported by a H2020 Marie Sklodowska-Curie European Research Fellowship. He was recognized as an Outstanding Reviewer of the IEEE TRANSACTIONS ON ANTENNAS AND PROPAGATION, in 2014 and 2020. He was also the Founder and First Chairman of the IEEE AP-S and IEEE MTT-S Joint Chapters in Canada and Scotland, in 2014 and 2019 , respectively. In recognition of these services, he was presented with an Outstanding Volunteer Award from IEEE in 2015, and in 2020, MTT-S recognized this Scotland Chapter for its activities and it was awarded the winner of the Outstanding Chapter Award. He has also served as a Lecturer for the European School of Antennas and Associate Editor for the IET Electronics Letters. He is currently a Guest Associate Editor of the IEEE OPEN JOURNAL OF ANTENNAS AND PROPAGATION and IEEE ANTENNAS AND WIRELESS PROPAGATION LETTERS. He was also the recipient of the Outstanding Dissertation Award for his Ph.D.

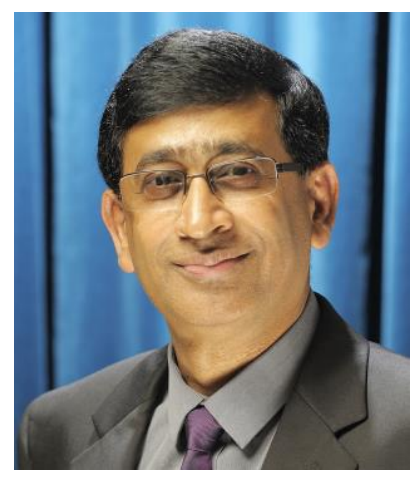

Goutam Chattopadhyay (Fellow, IEEE) received the Ph.D. degree in electrical engineering from the California Institute of Technology (Caltech), Pasadena, CA, USA, in 2000.

$\mathrm{He}$ is a Senior Research Scientist with the NASA's Jet Propulsion Laboratory, California Institute of Technology, and a Visiting Associate with the Division of Physics, Mathematics, and Astronomy, California Institute of Technology, Pasadena, CA, USA. He has authored or coauthored more than 350 publications in international journals and conferences and holds more than 20 patents. His research interests include microwave, millimeter wave, and terahertz receiver systems and radars, and development of terahertz instruments for space applications.

Dr. Chattopadhyay was the recipient of more than 35 NASA technical achievement and new technology invention awards, the IEEE Region-6 Engineer of the Year Award in 2018, the Distinguished Alumni Award from the Indian Institute of Engineering Science and Technology, India, in 2017, the Best Journal Paper Award in 2020 and 2013 by the IEEE TRANSACTIONS ON TERAHERTZ SCIENCE AND TECHNOLOGY, the Best Paper Award for antenna design and applications at the European Antennas and Propagation conference in 2017, and the IETE Prof. S. N. Mitra Memorial Award in 2014. He is an elected AdCom member of the IEEE MTT Society and is the Chair of the Meetings and Symposia Committee. He is a Fellow of IETE (India) and an IEEE Distinguished Lecturer.

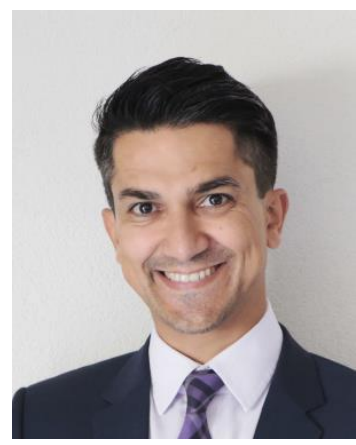

Nelson J. G. Fonseca (Senior Member, IEEE) received the M.Eng. degree from Ecole Nationale Supérieure d'Electrotechnique, Electronique, Informatique, Hydraulique et Télécommunications (ENSEEIHT), Toulouse, France, in 2003, the M.Sc. degree from the Ecole Polytechnique de Montreal, Quebec, Canada, also in 2003, and the PhD degree from Institut National Polytechnique de Toulouse Université de Toulouse, France, in 2010, all in electrical engineering.

He currently works as an Antenna Engineer with the Antenna and Sub-Millimetre Waves Section, European Space Agency (ESA), Noordwijk, The Netherlands. Since November 2020, he has held an Honorary Appointment as Professional Fellow at the University of Technology Sydney (UTS), Australia. His current research interests include multiple beam antennas for space missions, beamformer theory and design, ground terminal antennas and novel manufacturing techniques. He has authored or co-authored more than 230 papers in peer-reviewed journals and conferences and has over 50 patents issued or pending.

Dr. Fonseca is currently serving as an Associate Editor for the IET Microwave, Antennas and Propagation (MAP) and for the IEEE Transactions on Microwave Theory and Techniques (TMTT), and as a Topic Editor for the IEEE Journal of Microwaves $(J M W)$. He is also serving as Co-Vice Chair of the newly founded IEEE MTT-S Technical Committee 29 (TC-29) on Microwave Aerospace Systems. He is a board member of the European School of Antennas (ESoA) since January 2019 and is actively involved both as lecturer and as coordinator in courses related to space and ground antennas. He is the elected EurAAP Regional Delegate representing Benelux for the term 2021-2023. He received several prizes and awards, including the Best Young Engineer Paper Award at the $29^{\text {th }}$ ESA Workshop on Antennas in 2007, an ESA Teamwork Excellence Award in 2020, and several ESA Technical Improvement Awards. 